Canadian Science Publishing

Canadian Journal of Physiology and Pharmacology Revue canadienne de physiologie et pharmacologie

\title{
Protective effects of Zygophyllum album extract against deltamethrin-induced hyperglycemia and hepato-pancreatic disorders in rats
}

\begin{tabular}{|r|l|}
\hline Journal: & Canadian Journal of Physiology and Pharmacology \\
\hline Manuscript ID & cjpp-2016-0132.R1 \\
\hline Danuscript Type: & Article \\
\hline Complete List of Authors: & $\begin{array}{l}\text { Anouar, Feriani; Laboratory of Animal Ecophysiology, Faculty of Science } \\
\text { of Sfax, 3018 Sfax, Tunisia } \\
\text { Hachani, Rafik; Laboratory of Vascular Pathologies, Integrated Physiology } \\
\text { Unit, Faculty of Sciences of Bizerte, 7021 Jarzouna, Tunisia } \\
\text { Kaabi, Belhassen; Laboratory of Epidemiology and Veterinary } \\
\text { Microbiology, Institut Pasteur de Tunis, BP 74, 1002 Belvedere-Tunis, } \\
\text { Tunisia } \\
\text { Ncir, Marwa ; FSS, Sfax } \\
\text { Elfeki, Abdelfattah; Laboratory of Animal Ecophysiology, Faculty of Science } \\
\text { of Sfax 3018 Sfax, Tunisia } \\
\text { Allagui, Mohamed; Laboratory of Animal Ecophysiology, Faculty of } \\
\text { Science of Sfax, 3018 Sfax, Tunisia }\end{array}$ \\
\hline Keyword: & \begin{tabular}{l} 
Zygophyllum album, deltamethrin, hyperglycemia, pancreatic, hepatic \\
\hline
\end{tabular} \\
\hline \multicolumn{2}{|c}{} \\
\hline
\end{tabular}


1 Protective effects of Zygophyllum album extract against deltamethrin-induced hyperglycemia and hepato-pancreatic disorders in rats.

3

4 Feriani Anouar, ${ }^{\mathbf{a}, \mathbf{b}}$ Hachani Rafik, ${ }^{\mathbf{c}}$ Kaabi Belhassen, ${ }^{\mathbf{d}}$ Ncir Marwa, ${ }^{\mathbf{a}}$ El Feki Abdelfatteh ${ }^{\mathbf{a}}$ 5 and Allagui Mohamed Salah ${ }^{\text {a }}$

6 a Laboratory of Animal Ecophysiology, Faculty of Science of Sfax, 3018 Sfax, Tunisia

7 b ${ }^{\mathbf{b}}$ Research Unit of Macromolecular Biochemistry and Genetics, Faculty of Sciences of Gafsa, 82112 Gafsa, Tunisia

9 c Laboratory of Vascular Pathologies, Integrated Physiology Unit, Faculty of Sciences of 10 Bizerte, 7021 Jarzouna, Tunisia

11 d Laboratory of Epidemiology and Veterinary Microbiology, Institut Pasteur de Tunis, BP 74, 121002 Belvedere-Tunis, Tunisia

13

14

15 Correspondence to:

16 Feriani Anouar

17 feriani.anouar@yahoo.fr
18

19

20

21

22

23

24

25 


\section{Abstract}

27 The current study was designed to investigate the possible mechanism involved in hyperglycemia 28 induced by chronic exposure to deltamethrin (DLM) in rat and to assess whether this damage is 29 amenable to modulation by Zygophyllum album. DLM, a synthetic pyrethroid pesticide, was 30 administrated at a dose of $4 \mathrm{mg} / \mathrm{kg}$ bw, during 60 days. Compared with control, DLM showed a 31 significant increase of blood glucose $(p \leq 0.01)$ and glycosylated hemoglobin levels $(p \leq 0.01)$ and 32 a clear decrease $(p \leq 0.01)$ of insulin and total hemoglobin levels. In addition, hepatic glycogen 33 content and the activity of hexokinase decreased $(p \leq 0.01)$, whereas the activities of glucose-634 phosphatase and glycogen phosphorylase were significantly increased $(p \leq 0.01)$. Moreover, 35 pancreatic lipid peroxidation (TBARS level) was higher $(p \leq 0.01)$ and oxidative stress 36 biomarkers (SOD, CAT, GPX and GSH) were altered owing to DLM toxicity. However, $Z$. 37 album, when combined with DLM, it significantly ameliorated almost all the hepato-pancreatic 38 disorders induced by DLM alone. Furthermore, Z. album supplement were found to be effective in 39 preserving the normal histological appearance of hepatic and pancreatic tissue. In conclusion, this 40 study suggested that, owing to its antioxidant effects, MEZAL can potentially prevent the 41 hyperglycemia observed in DLM-treated.

42

43 Keywords: Zygophyllum album, deltamethrin, hyperglycemia, pancreatic, hepatic. 
47

48

49

50

51

52

53

54

55

56

57

58

59

60

61

62

63

64

65

66

67

68

69

70

71

\section{Introduction}

The synthetic pyrethroids is a one of the most popular classes of pesticides currently used in agriculture, horticulture, forestry and public health because they are environmentally compatible by virtue of their moderate persistence, slow aqueous mobility in soil and low volatility (Erstfeld 1999). Deltamethrin (DLM) is one of the effective pyrethroid pesticide widely used extensively in the agriculture and domestic applications to control a broad spectrum of insect pests (Barlow et al. 2001). Consequently, theses pesticides can find their way into water reservoirs, streams and rivers, thus leading to adverse impacts on the aquatic organisms, animals and human health (John and Prakash 2003). Owing to its lipophilic nature, deltamethrin causes a number of toxic effects including reproductive toxicity (Benhalima et al. 2014; Chargui et al. 2009), hematotoxicity (El-Demerdash et al. 2004), hepatic dysfunction (Chargui et al. 2012), and neurotoxicity (Wolansky and Harrill 2008). Among other effects, deltamethrin has been reported to cause oxidative stress and generate reactive oxygen species (ROS) (Tuzmen et al. 2008), leading to lipid peroxidation, damage to DNA, and protein degradation (Chen et al. 2007). In addition, deltamethrin can dispose of much of the fat that enters the liver, and dysfunction in this pathway could promote the development of the nonalcoholic fatty liver disease (NAFLD). Indeed, lipids play a crucial role in the pathogenesis of diabetes mellitus (Mnafgui et al. 2015). In clinical investigation, the NAFLD is strongly correlated with insulin-resistant states such as type 2 diabetes mellitus (T2DM), and they are linked to an imbalance between apoptosis and anti apoptosis balance (Tarantino et al. 2011b). Moreover, several studies in experimental animal models and humans indicate a strong association between the severity of NAFLD and degree of mitochondrial dysfunction and oxidative stress (Soardo et al. 2011; Tarantino et al. 2011a; Videla et al. 2004). Recently, the most clinical studies have reported that long-term exposure to pesticide provokes glucose metabolism disturbance and insulin resistance (Raafat et al. 2012; Saldana et al. 2007; Slotkin 
2011). Whereas, the mechanism(s) involved in the blood glucose alterations following xenobiotics exposure have been under investigation in the recent years. Liver and pancreas are the essentially organs that control the regulation of glucose. The liver maintains the balance between the uptake and the storage of glucose via glycogenesis, and the release of glucose by the activation of processes of glycogenolysis and gluconeogenesis (Abdollahi et al. 2003). In the other hand, pancreas plays an important role in glucose homeostasis by hormonal regulation, in particular, the insulin and glucagon, and by the activation of the system transporting glucose to targeted cells. Moreover, Lasram et al. (2009) have showed that the hyperglycemia observed following malathion exposure, can be explained by a stimulation of glycogenolysis and gluconeogenesis by liver, with a temporarily loss of endocrine functions of pancreas. Furthermore, Sivakumar et al. (2009) have suggested that endogenous hepatic glucose production is increased as a result of impaired activities of the key enzymes of carbohydrate metabolism.

To prevent insulin resistance and diabetes, many synthetic drugs are available. However, most of them have been reported to cause serious side effects, when used for long time (Harrower 1994; Kiefer et al. 2004). Accordingly, a growing trend is toward the use of plant extracts, which contain a wide variety of antioxidants molecules, such as, phenolic acids, flavonoids and tannins (Corns 2003). During the past few years, halophytes have attracted the attention of researchers because they are potential sources of valuable antioxidants and have shown to exhibit various biological activities and therapeutic properties (Ksouri et al. 2008). The Zygophyllum species that belongs to the Zygophyllaceae family are one of the most abundant halophytes in the Mediterranean and Middle East regions. They represent a group of succulent plants that are drought resistant and/or salt tolerant, living under severe dry climatic conditions (Hammad and Qari 2010). In Tunisia, Zygophyllum album is one of the famous herb drug widely distributed in arid regions. This plant has many traditional uses including 
97 antispasmodic, antirheumatic, antieczema. It is also used as diuretic, antihistaminic and local 98 anaesthetic agent (Moustafa et al. 2007). Research undertaken on Z. album showed that the 99 dichloromethane extract of Z. album had appreciable in vitro anticancer capacity against 100 human lung carcinoma and colon adenocarcinoma cells (Ksouri et al. 2013). In addition, 101 recent studies in experimental animals have showed that ethanol extract of Z. album had a 102 potent anti-inflammatory effect, which is manifested by decreases in CRP and TNF- $\alpha$ levels. 103 Moreover, this extract had an antihyperlipidemic effect (Elgoul et al. 2012a,b) and could 104 reduce the hepatotoxicity and nephrotoxicity by reverted back near to normal the values of the 105 liver-kidney dysfunction indices (Mnafgui et al. 2012). Even more, it has been reported that 106 oral administration of the essential oil from Z. album in experimental diabetic rats attenuated 107 symptoms of diarrhea, improved lipid disorders, and hypertension through inhibiting the 108 pancreatic lipase and angiotensin-converting enzyme (ACE) activities (Mnafgui et al. 2015).

109 To the best of our knowledge, the protective effects of Z. album have never been studied in 110 experimental rats exposed to pesticide. Indeed, the present study was designed to investigate 111 the antioxidant activities of MEZAL in vitro and to evaluate its possible protective effect 112 against deltamethrin-induced hypergylcemia in rats. Thus, some of blood, hepatic and 113 pancreatic key parameters of glucose homeostasis were studied. Moreover, anti- and pro114 oxidant statuses, as well as histologic study of liver and pancreatic tissues, were explored too.

\section{2. Materials and methods}

\section{2.1. Chemicals}

118 Deltamethrin, is a synthetic pyrethroid insecticide (C22H19Br2NO3). The CAS chemical

119 name is (a\&cyano\&3\&phenoxybenzyl (1R,3R)\&3\&(2,2\&dibromovinyl) \& 2,2 dimethyl

120 cyclopropanecarboxylate) and all other chemical products required for all biochemical assays

121 was obtained from sigma Aldrich Co. (Germany). 


\subsection{Plant source and preparation of extract}

124 Leaves of Z. album were collected from Nefta (south of Tunisian) in May 2015. The studied 125 specie was identified by Dr. Abbes Zouhaeir, Faculty of Sciences of Gafsa, Tunisia and

126 voucher specimens are kept at the herbarium of the Department of Life Sciences in the

127 Faculty of Sciences of Gafsa. The Leaves were rinsed, shade dried, and reduced to fine

128 powder. $200 \mathrm{~g}$ of the dried powder was extracted with $2000 \mathrm{ml}$ of methanol (80\%) by

129 maceration for $48 \mathrm{~h}$ with frequent agitation, then the extracts were centrifuged and the

130 supernatant was evaporated under reduced pressure to remove methanol. The dried extracts 131 were stored at $-20^{\circ} \mathrm{C}$ until use.

132

\section{2.3. In vitro antioxidant activity of MEZAL}

134 Hydroxyl radical scavenger ability of the methanolic extract of Z. album was measured using

135 the method described by Smirnoff and Cumbes (1989). Hydroxyl radical was generated from

136 Fenton reaction $\left(\mathrm{FeSO}_{4}-\mathrm{H}_{2} \mathrm{O}_{2}\right)$. The ability of MEZAL to scavenge hydrogen peroxide was

137 determined according to the method describe by Ruch et al. (1989). The percentage inhibition

$138(\mathrm{I} \%)$ of free radical was calculated with the following formula:

$139 \mathrm{I} \%=\left[\left(\mathrm{A}_{\text {blank }}-\mathrm{A}_{\text {sample }}\right) / \mathrm{A}_{\text {blank }}\right] * 100$

140 Radical scavenging capacity is expressed as an $\mathrm{EC}_{50}$ value, which is the effective

141 concentration of the sample required to scavenge $50 \%$ of the free radicals present in the test 142 solution. BHT was used as a reference compound.

144 2.4. Animals and experimental design

145 Adult male Wistar rats (weighing 180 - $200 \mathrm{~g}$ ) were purchased from (SIPHAT, Tunisia). They

146 all received a standard pellet diet purchased from the Industrial Society of Rodents' Diet 
147 (SNA, Sfax, Tunisia) and water ad libitum. All animal procedures were conducted in strict

148 conformation with the local Institute Ethical Committee Guidelines for the Care and Use of

149 laboratory animals of our institution. The rats were kept in metabolic cages and were housed

150 under controlled conditions $\left(22-25^{\circ} \mathrm{C}\right)$ on a 12-h light/12-h dark cycle.

151 After two weeks of acclimatization, the animals were randomly divided into four different

152 groups; six animals each. Control group, animals were given $1 \mathrm{ml}$ of corn oil. Z. album treated

153 group (MEZAL), animals were received daily methanolic extract of Z. album dissolved in

154 corn oil (400 mg/kg bw) (Mnafgui et al. 2014); Deltamethrin treated group (DLM) animals

155 were treated daily with deltamethrin in corn oil at a dose of $4 \mathrm{mg} / \mathrm{kg}$ bw (1/10 LD50) (Aydin

156 2011). Finally, animals received both deltamethrin and methanolic extract of Z. album

157 (DLM+MEZAL). All the groups were treated orally (by gavage) for 60 consecutive days.

\subsection{Sample collection}

160 At the end of experimental period, the animals were fasted for 12 hours and sacrificed by

161 cervical decapitation to avoid stress conditions. Blood samples were collected into EDTA

162 tubes for the estimation of plasma glucose and insulin. Hemoglobin and glycosylated

163 hemoglobin levels were estimated in whole blood samples.

164 The liver and pancreas tissue was dissected out, washed in ice-cold saline to remove the 165 blood, and then a portion of the tissues was collected in $10 \%$ formalin solution and 166 immediately processed for histological study by the paraffin technique.

167 Liver tissue was minced and homogenized in $0.1 \mathrm{M}$ Tris- $\mathrm{HCl}$ buffer (pH 7.4) and 168 centrifuged $(3000 \times \mathrm{g}$ for $10 \mathrm{~min})$. The resulting supernatant was used for the assay of 169 key enzymes of carbohydrate metabolism. Another portion of wet liver tissue was used for 170 the estimation of glycogen content. 
172 2.6. Determination of blood glucose, plasma insulin and glycosylated hemoglobin levels

173 Plasma glucose level was assayed by enzymatic methods based on the oxidase/peroxidase

174 system, using commercial reagent kits, and the results were expressed as mg glucose/dl.

175 Plasma insulin content was assayed by multi-well plate reader using the rat insulin ELISA kit,

176 according to the manufacturer's protocol. Total hemoglobin $(\mathrm{Hb})$ and glycosylated

177 hemoglobin (HbA1c) in whole blood were spectrophotometrically analyzed by the method of

178 Drabkin and Austin (1932). All test kits were purchased from Biomaghreb (Ariana, Tunisia).

\subsection{Measurement of carbohydrate metabolic enzymes}

181 The activities of Glucose-6-phosphatase (EC 3.1.3.9) and glycogen phosphorylase

182 (EC 2.4.1.1) were performed as previously described by Koide and Oda (1959) and Nieymer

183 et al. (1961), respectively, then were expressed as $\mu \mathrm{mol}$ of Pi liberated $/ \mathrm{min} / \mathrm{mg}$ protein. The

184 activity of hepatic hexokinase (EC 2.7.1.1) was estimated by the method of Lapeir and

185 Rodnick (2001) then was expressed as $\mu \mathrm{mol}$ glucose phosphorylated $/ \mathrm{min} / \mathrm{mg}$ of protein.

$187 \quad 2.8$. Hepatic glycogen assay

188 Glycogen content was determined following the technique of Ong and Khoo (2000). The 189 results were expressed in $\mathrm{mg}$ of glycogen/ $\mathrm{g}$ of liver.

191 2.9. Evaluation of pancreatic oxidative stress biomarkers

192 About $0.5 \mathrm{~g}$ of excised pancreas was homogenized into 2-ml ice-cold lyses buffer (pH 7.4), 193 sonicated twice, and centrifuged for $20 \mathrm{~min}$ at $3000 \times \mathrm{g}$ and $4{ }^{\circ} \mathrm{C}$. The collected supernatants 194 were used for the determination of thiobarbituric acid reactive substances (TBARS) 195 concentration, protein carbonyl levels and antioxidant enzyme activities. In this context, lipid 196 peroxydation level was measuring by the quantification of TBARS according to Buege and 
197 Aust (1972). In addition, protein carbonyls (PC) level was determined using the method of

198 Levine et al. (1990). In this method, carbonyl group of proteins was measured in the resulting

199 pellets by reaction with 2, 4-dinitrophenylhydrazine to form protein hydrazone which was 200 measured spectrophotometrically at $370 \mathrm{~nm}$.

201 Total superoxide dismutase (CuZn-SOD and Mn-SOD) activity was estimated 202 spectrophotometrically according to Marklund and Marklund (1974). The absorbance was 203 measured at $560 \mathrm{~nm}$ and the activity was expressed as units/mg of proteins. Catalase (CAT) 204 activity was determined in pancreas supernatants by measuring hydrogen peroxide 205 decomposition at $240 \mathrm{~nm}$ according to Aebi (1984). Glutathione-peroxidase (GPX) activity 206 was assayed by the subsequent oxidation of NADPH at $340 \mathrm{~nm}$, using the method described 207 by Flohe and Gunzler (1984).

208 Total GSH and thiols contents were measured by Ellman's methods (Ellman 1959). The 209 protein concentration was estimated by the method of Bradford (1976) using bovine serum 210 albumin as a standard.

\section{$212 \quad$ 2.10. Histological study}

213 Liver and pancreas tissues were cut into small slices, and fixed in $10 \%$ buffered formalin,

214 processed using a graded ethanol series, and then embedded in paraffin. The paraffin sections

215 were cut into 5- $\mu \mathrm{m}$ thick slice. The pancreas was stained with hematoxylin and eosin, and the

216 liver with periodic acid schiff (PAS) to show the glycogen deposition in hepatocytes. The

217 sections were viewed by a light microscopic and then photographed.

218

219

\subsection{Statistical Analysis}

220 Results were expressed as mean \pm standard deviation (mean $\pm \mathrm{SD}$ ). All analyses were carried 221 out with GraphPad Prism 4.02 (GraphPad Software, San Diego,CA). Significant differences 
222 between treatment were determined by one-way analysis of variance (ANOVA), followed by 223 Tukey's test to correct for multiple comparisons with acceptable statistical level of 224 significance set to 0.05 .

225

226

\section{Results}

227

\subsection{In vitro antioxidant properties}

As shown in figure 1, MEZAL has a dose-dependent scavenging effect on both radical HO and hydrogen peroxide, compared to BHT $\left(r^{2}=0.987\right)$. In the same context, $\mathrm{EC}_{50}$ values for $\mathrm{HO}$ and $\mathrm{H}_{2} \mathrm{O}_{2}$ scavenging activity were $335.83 \pm 1.05$ and $335.44 \pm 1.1$, respectively. Whereas the $\mathrm{EC}_{50}$ values of $\mathrm{BHT}$ were $265.65 \pm 1.22$ and $263.28 \pm 2.68 \mu \mathrm{g} / \mathrm{mL}$, respectively.

\subsection{Acute toxicity}

234 The dose of methanolic extract of Z. album (MEZAL) was non-toxic during the experiment.

235 The lethality was found to be zero in the groups received $400 \mathrm{mg} / \mathrm{kg} / \mathrm{bw}$ of MEZAL.

\subsection{Effect of MEZAL on biochemical parameters}

238 Table 1 depicts the levels of plasma glucose, insulin, $\mathrm{Hb}$ and $\mathrm{HbA} 1 \mathrm{c}$ in control and

239 experimental groups. Deltamethrin caused a significant $(p<0.001)$ increase in blood glucose and glycosylated hemoglobin levels as compared to the control group. Whereas, co-treatment with methanolic Z. album extract (DLM + MEZAL group) provoked significant decrease in

242 these levels, as compared to deltamethrin treated group (DLM). Moreover, the levels of 243 insulin and $\mathrm{Hb}$ were significantly $(p<0.001)$ decreased in the DLM-treated group. However, 244 those levels were improved towards near normal on animals treated with MEZAL. 
247

248

249

250

251

252

253

254

255

256

257

258

259

260

261

262

263

264

265

266

267

268

269

270

271

\section{0}

\subsection{Carbohydrate metabolic enzymes changes}

Table 2 depicts the activities of carbohydrate metabolic enzymes hexokinase, glucose-6phosphatase, and glycogen phosphorylase in liver tissue of control and all experimental groups. Deltamethrin treatment showed a significant $(p<0.05)$ elevation in the activities of glucose-6-phosphatase and glycogen phosphorylase, while the activity of hexokinase was significantly $(p<0.001)$ decreased. Oral co-administration of MEZAL to deltamethrin-treated animals significantly improved these parameters changes.

\subsection{Effect of MEZAL on hepatic glycogen level}

The treatment of rats with deltamethrin caused significant $(p<0.001)$ marked decrease in the hepatic glycogen content when compared to control group (Table 2). Simultaneous treatment of rats with deltamethrin and MEZAL caused a significant increase in the hepatic glycogen levels as compared to those treated with deltamethrin alone. However, there were no significant differences observed for the glycogen levels in rats treated with the MEZAL when compared to control group ( $p \geq 0.05)$.

\subsection{Lipid peroxidation and protein carbonyl changes}

As shown in table 3, there was a significant increase in lipid peroxidation (TBARS) and protein carbonyls (PC) levels $(p<0.001)$ in the pancreatic organ of the deltamethrin (DLM) treated- group, as compared to control group. Further, methanolic Z. album extract and deltamethrin co-administration together (DLM + MEZAL group) has significantly lowered the lipid peroxidation and protein carbonyl contents in the pancreas homogenate, which remained near to that of control group. 


\section{3.7. Antioxidant enzymes and GSH pancreatic changes}

273 The changes in the enzyme activities of the pancreatic samples of all treated groups were

274 evaluated (Table 4). The results revealed significant decreases in superoxide dismutase 275 (SOD), catalase (CAT) and glutathion peroxidase (GPX) activities in DLM group, as 276 compared to control group. Interestingly, chronic treatment with MEZAL showed significant

277 restoration in these enzymatic antioxidants activities in pancreas supernatant. Similarly, total 278 GSH contents were lowered in deltamethrin (DLM) treated group, compared with the control 279 group. While, a significant increase in these non- enzymatic antioxidant biomarker were 280 observed in DLM + MEZAL group.

\subsection{Histopathology examinations}

283 H\&E staining of pancreatic sections of the all treated groups are shown in Figure 2. There 284 were no remarkable alterations in the pancreatic architecture observed in control and MEZAL 285 treated rats (Fig. 2A, B), whereas a reduction in the size of islets, an extensive necrosis, a mild 286 atrophy of islets and the residue of damaged $\beta$-cell population were found in the pancreas of 287 DLM treated group (Fig. 2C). However, histological examination of the DLM + MEZAL treated rats revealed significantly reduced injuries in pancreas manifested by an increase of $\beta$ cell number and size of the islets (Fig. 2D).

290 Glycogen content in paraffin sections of rat liver stained with PAS method are shown in

291 figure 3 . In the liver cells of the control group, a normal content of glycogen revealed by a 292 large number of magenta-colored fine granules distributed throughout the cytoplasm of the 293 hepatocytes (Fig. 3A). A noticeable decrease in the deposit of glycogen was observed in the 294 deltamethrin treated group when compared to the control (Fig. 3C). However, in deltamethrin 295 and MEZAL treatment (Fig. 3D), we noticed an important granule of glycogen in the 296 cytoplasm of hepatocytes when compared to deltamethrin-treated animals. 


\section{Discussion}

299 Hyperglycemia has been largely considered as one of the effects in poisoning by pesticide in 300 human (Montgomery et al. 2008). Researchers have found that natural antioxidants derived 301 from plant can be used for the treatment of hyperglycemia (Yolanda and Adriana 2006). 302 Zygophyllum album is one of the important antidiabitic plants used in traditional medicine.

303 However, there are no previous studies regarding the biological effects of $Z$. album against 304 deltamethrin toxicity. Therefore, in this present study, an attempt has been made to know the 305 possible mechanism of action through which deltamethrin induced hyperglycemia and 306 perturbations on hepatic and pancreatic function in rats and the role of $Z$. album in ameliorating 307 its toxic effects. The antioxidant properties in vitro of the MEZAL were investigated. The 308 methanolic extract exhibited a significant hydroxyl radical scavenging activity and inhibited $\mathrm{H}_{2} \mathrm{O}_{2}$ in a dose-dependent pattern at all concentrations. Indeed, the potential scavenging

310 ability observed in this work could be due to the presence of phenolic compounds in the leave 311 extracts. Ksouri et al. (2013) have suggested that antioxidant activities of different extract of 312 Z. album can be attributed to the presence of triterpenes, flavonoids and sterols in this plant, 313 which are widely known as powerful antioxidants and used in various industrial fields.

314 The obtained antioxidant aptitude in this study can make MEZAL an excellent candidate for 315 prevention against the in vivo deltamethrin-induced change on glucose homeostasis in rats. In 316 previously experimental studies, the hyperglycemia is considered the most important 317 complications found under organopesticides, including pyrethroids administration (Abdollahi 318 et al. 2004). The present work revealed that chronic exposure to deltamethrin was associated 319 with increase of blood glucose concentration and a decrease of plasma insulin levels. 320 Similarly, Ibiang et al. (2013) and Yousef et al. (2003) described the hyperglycemia in rabbits 321 and in rats exposed to a single intraperitoneal injection of deltamethrin. The sever 322 hyperglycemia and hypoinsulinemia conditions in the present work might be associated to the 
323 alteration of pancreatic cells which was confirmed by the obtained histopathological results in

324 this study. Many reports have suggested that the observed hyperglycemia due to insecticides

325 toxic effects is a result of pancreatic $\beta$ cell dysfunction that leading to insufficient insulin 326 secretion (Pournourmohammadi et al. 2005).

327 In our study, the levels of both plasma glucose and insulin were significantly reversed after 328 MEZAL-treatment at the concentration of $400 \mathrm{mg} / \mathrm{kg}$ for 60 days. The antihyperglycemic 329 potential of MEZAL could be due to the increased release of insulin from the existing $\beta$ cells 330 population of the islets of langerhans and enhanced utilization of glucose by peripheral 331 tissues. This hypothesis was further confirmed by the results of the histopathological 332 examination that revealed an increase of $\beta$-cell number and size of the islets in DLM + 333 MEZAL-treated rats. Indeed, the possible antihyperglycemic effects of $Z$. album can be 334 attributed to its antioxidant properties (Elgoul et al. 2012b; Mnafgui et al. 2012). Previous 335 studies have demonstrated that Z. album and many plants belonging to the genus Zygophyllum 336 have been recommended against hyperglycemia (El Ghoul et al. 2014; Jaouhari et al. 2000).

337 Additionally, in experimental diabetic animals, El Ghoul et al. (2012a) have reported that the 338 ethanolic extract of Z. album at a dose of $300 \mathrm{mg} / \mathrm{kg}$ has antihyperglycemic activity with a 339 stimulatory effect on insulin release. In accordance, previous investigations have shown that 340 other halophytes medicinal plants, such as Scoparia dulcis and Gymnema montanum, as well 341 as some plant products, like morin, fraxetin and eugenol can protects the pancreatic $\beta$-cells 342 and thereby stimulates the remnant pancreatic $\beta$-cells to synthesize and secrete more insulin 343 (Ananthan et al. 2003; Murali et al. 2013; Pari et al. 2005;).

344 Recent studies showed that the induction of oxidative stress is one of the main mechanisms of 345 deltamethrin toxicity (Tuzmen et al. 2008). It is evident that oxidative stress plays a key role 346 in causing insulin resistance and $\beta$-cell dysfunction by their ability to activate stress-sensitive 347 signaling pathways (Evans et al. 2003). However, to our knowledge, deltamethrin-induced 
348

349

350

351

352

353

354

355

356

357

358

359

360

361

362

363

364

365

366

367

368

369

370

371

oxidative stress in pancreas and its involvement in the ensuing hyperglycemia have not been reported. In the present study, we observed significant increase in the level of MDA and protein carbonyl content in the pancreas of deltamethrin-exposed rats which confirm the oxidative damage in pancreatic tissues. MDA and PC content are indicative of lipid peroxidation and protein oxidation in the tissues studied. Accumulating MDA level in lipid bilayer membrane of pancreas can provoke loss of its integrity and support the liberation of pancreatic enzymes into circulation (Abdollahi et al. 2004). Additionally, oxidation of protein further disrupts cellular metabolism by actively degrading key enzymes and regulating protein factors. Furthermore, glutathione, the most abundant cellular non-protein thiol, was depleted in pancreas of the rats. The depletion of GSH associated with increased MDA and PC content confirmed the occurrence of oxidative stress on the dysfunction of the endocrine function of pancreatic islets and loss of glucose control. Indeed, Kamath et al. (2007) have suggested the contribution of the oxidative stress in dimethoate-induced pancreatic damage/dysfunction leading to acute pancreatitis and hyperglycemia. Superoxide dismutase (SOD), catalase (CAT), and glutathione-peroxydase (GPx), as antioxidant enzymes, are first line of the defense. In this study it was clear that deltamethrin intoxication inhibited SOD, CAT and GPx activities in rat pancreas. In agreement with our results, Kamath et al. (2008) found that dimethoate induced pancreatic oxidative damage by altering SOD and CAT activities.

The co-administration of deltamethrin and MEZAL significantly decreased the oxidative stress in the pancreas. Indeed, MEZAL pretreatment significantly reduced lipid peroxidation and protein oxidation in pancreas. Furthermore, MEZAL treatment ameliorated the levels of SOD, CAT and GPx when compared to DLM-treatment. The protective effect of MEZAL could be explained by its ability to reduce the level of oxidative stress by the inhibition of ROS generation. Mnafgui et al. (2014) showed that the ethanol extract of Z. album helped to 
372 protect the $\beta$-cells structure and function in diabetic rats via reduction of ROS production and 373 ameliorated the activities of antioxidant enzymes.

374 Normal levels of glucose produce a normal amount of glycated hemoglobin. When the level 375 of plasma glucose increases the fraction of glycated hemoglobin increases in a predictable 376 way, and the total $\mathrm{Hb}$ level is decreased (Koeing et al. 1976). In our study, administration of 377 MEZAL for 60 days prevented a significant elevation in HbA1c thereby increasing the level 378 of $\mathrm{Hb}$ in DLM + MEAZL-treated rats. This could be due to the restoration of blood glucose 379 level, thereby reducing the level of $\mathrm{Hb}$ glycosylation during the experimental period. This 380 result is in consistent with study of Mnafgui et al. (2015), which showed that administration of 381 essential oil of Zygophyllum album (OZA) significantly decreased the level of HbA1c in 382 diabetic rats.

383 Maintenance of normal blood glucose levels is a particularly important function of the liver. 384 Indeed, this organ plays a key role in glycolysis and gluconeogenesis (Pari and Srinivasan 385 2010). Recently, many experimental and clinical studies point out that in case of 386 hyperglycemia or in induced diabetes, the hepatic enzyme activity of carbohydrate 387 metabolism are markedly modulated (Sundaram et al. 2012). In this study we investigated, for 388 the first time, the activities of hexokinase, the first enzyme of glycolysis, and glucose-6389 phosphatase after 60 days of exposure to deltamethrin. Our data has demonstrated that 390 deltamethrin decrease the hexokinase activity, whereas significant reversal in the activity of 391 hexokinase was detected after oral administration of MEZAL to deltamethrin-treated rats.

392 Previous studies have showed that in the absence of insulin hexokinase enzyme is almost 393 completely inhibited in the rat liver (Gupta et al. 1999). Therefore, the elevated levels of 394 insulin observed in DEL + MEZAL group lead to the increased hexokinase activity in the 395 hepatic tissues there by increased glycolysis, as a result, a controlled glucose homeostasis 396 were observed. 
397 On the other hand, results showed that administration of deltamethrin increased significantly

398 the activity of glucose-6-phosphatase, enzyme implicated in mechanism of gluconeogenesis.

399 Similar results were observed after the administration of acephate and chlorpyrifos (Acker

400 and Nogueira 2012; Joshi and Rajini 2009). MEZAL modulated positively the activity of this

401 enzyme leading to reducing the endogenous production of glucose.

402 The glycogen is considered the major storage form for carbohydrates in animals, and is the 403 immediate source of energy. Glycogen synthase and glycogen phosphorylase are the rate-

404 limiting enzymes in glycogen metabolism (Pederson et al. 2005). According to our result, 405 deltamethrin impaired the normal capacity of the liver rat to synthesize glycogen, and 406 increased the activity of glycogen phosphorylase. This finding could be due to a state of 407 insulin deficiency, as has been reported by Parker et al. (2004). A gradual depletion of liver 408 glycogen level in response to pesticides is also observed in albino rats (Ksheerasagar and 409 Kaliwal 2003). The observed glycogen breakdown and increased activities of glycogen 410 phosphorylase in deltamethrin trated-rats were normalized in DLM + MEZAL treated rats, 411 which supported the possible role of MEZAL on the utilization and storage of glucose in the 412 hepatic tissues.

413 According to Ranjbar et al. (2010), dietary supplementation with antioxidants such as 414 polyphenols and flavonoids has beneficial effect on prevention or treatment against 415 pesticide-induced changes in glucose homeostasis. Indeed, the potent hypoglycemic effect 416 of MEZAL could be due to the high level of phytochemical compounds, such as kaempferol, 417 isorhamnetin, tannins, flavoinoids, isoquercitin, $\beta$-sitosterol, and triterpenes found in the 418 leaves of Z. album (Hussein et al. 2011; Moustafa et al. 2007).

419 420 421 


\section{CONCLUSIONS}

423 The current study suggests that hyperglycemia induced by deltamethrin could be mediated by

424 induction of oxidative stress in pancreas leading to a transient dysfunction of the endocrine

425 function of pancreatic islets and depletion of insulin secretion, as a result, a stimulation of

426 hepatic glycogenolysis and gluconeogenesis pathways. According to its antioxidant effect,

427 MEZAL could improve the glycemic status of deltamethrin treated-rats by stimulation of $\beta$

428 cell function and insulin secretion and modulating the key enzymes activities of carbohydrate

429 metabolism in hepatic tissue, such as hexokinase, glucose-6-phosphatase and glycogen

430 phosphorylase. However, further studies are needed to gain a better understanding of

431 the origin of oxidative stress. For this reason, it is interesting to determining the fat storage in

432 hepatocyte of deltamethrin treated group, and accordingly adhering to the hypothesis that the

433 exposure of hepatocytes to free fatty acids, resulting in increased ROS production and

434 mitochondrial damage. In addition, some other parameters such as Bcl-2 protein, cytochrome

435 c, triglycerides and unconjugated bilirubin, should be investigated.

436

437

438

439

440

441

442

443

444

445

446 


\section{Acknowledgements}

448 The authors would like to express their sincere gratitude to Mr. Rached Raddadi, Mr. Hafedh

449 Trabelsi and Mrs. Jihen, technicians at Anatomopathology Laboratory, Gafsa, Tunisia, for 450 their assistance in histological studies.

451

452

453

454

455

456

457

458

459

460

461

462

463

464

465

466

467

468

469

470

471 


\section{References}

473

474

475

476

477

478

479

480

481

482

483

484

485

486

487

488

489

490

491

492

493

494

495

496

497

498

499

500

501

502

503

504

505

506

507

508

509

510

511

512

513

514

515

516

517

518
Abdollahi, M., Chan, T.S., Subrahmanyam, V., and O'Brien, P.J. 2003. Effects of phosphodiesterase 3,4,5 inhibitors on hepatocyte cAMP levels, glycogenolysis, gluconeogenesis and susceptibility to a mitochondrial toxin. Mol. Cell. Biochem. 252: 205211.

Abdollahi, M., Donyavi, M., Pournourmohammadi, S., and Saadat, M. 2004. Hyperglycemia associated with increased hepatic glycogen phosphorylase and phosphoenolpyruvate carboxykinase in rats following subchronic exposure to malathion. Comp. Biochem. Physiol. C. 137: 343-347.

Acker, C.I., and Nogueira, C.W. 2012. Chlorpyrifos acute exposure induces hyperglycemia and hyperlipidemia in rats. Chemosphere, 89: 602-608.

Aebi, H. 1984. Catalase in vitro. Methods Enzymol. 105: 121 - 126.

Ananthan, R., Baskar, C., NarmathaBai, V., Pari, L., Latha, M., el al. 2003. Antidiabetic effect of Gymnemamontanum leaves: effect on lipid peroxidation induced oxidative stress in experimental diabetes. Pharmacol. Res. 48: 551-556.

Aydin, B. 2011. Effects of thiacloprid, deltamethrin and their combination on oxidative stress in lymphoid organs, polymorphonuclear leukocytes and plasma of rats. Pest. Biochem. Physiol. 100: 165-171.

Barlow, S.M., Sullivan, F.M., and Lines, J. 2001. Risk assessment of the use of deltamethrin on bednets for the prevention of malaria. Food Chem. Toxicol. 39: 407-422.

Benhalima, N., Benslima, A., Moalla, I., Fetoui, H., Pichon, C., et al. 2014. Protective effects of oat oil on deltamethrin-induced reprotoxicity in male mice. Food Funct. 5: 2070-2077.

Bradford, M.M. 1976. A rapid and sensitive method for the quantitation of microgramquantities of protein utilizing the principle of protein-dye binding. Anal. Biochem. 72: 248.

Buege, J.A., and Aust, S.D. 1972. Microsomal lipid peroxidation. Methods Enzymol. 51: $302-310$.

Chargui, I., Grissa, I., BenSassi, F., Hrira, M.Y., Haouem, S., et al. 2012. Oxidative stress, biochemical and histopathological alterations in the liver and kidney of female rats exposed to low doses of deltamethrin (DM): A molecular assessment. Biomed. Environ. Sci. 25: 672683 .

Chargui, I., Haouem, S., Haouas, Z., Zaouali, M., and BenCheikh, H. 2009. Toxic responses to deltamethrin (DM) low doses on gonads, sex hormones and lipoperoxidation in male rats following subcutaneous treatments. J. Toxicol. Sci. 34: 663-670.

Chen, D., Huang, X., Liu, L., and Shi, N. 2007. Deltamethrin induces mitochondrial membrane permeability and altered expression of cytochrome $\mathrm{C}$ in rat brain complications of sulfonylureas. J. Diabetes Complication, 8: 201- 203. 
Corns, C.M. 2003. Herbal remedies and clinical biochemistry. Ann. Clin. Biochem. 40:489507.

Drabkin, D.L., and Austin, H.J. 1932. Spectrophotometric studies. I. Spectrophotometric constants for common hemoglobin derivatives in human, dog and rabbit blood. J. Biol. Chem. 98: $719-733$.

El-Demerdash, F.M., Yousef, M.I., Kedwany, F.S., and Baghdadi, H.H. 2004. Role of alphatocopherol and beta-carotene in ameliorating the fenvalerate-induced changes in oxidative stress, hemato biochemical parameters, and semen quality of male rats. J. Environ. Sci. Health B. 39: 443-459.

El Ghoul, J., Boughattas, N.A., and Ben-Attia, M. 2012a. Antihyperglycemic and antihyperlipidemic activities of ethanolic extract of Zygophyllum album in streptozotocininduced diabetic mice. Toxico. Indust. Health, 29: 43-51

El Ghoul, J., Smiri, M., Ghrab, S., Boughattas,N.A., and Ben-Attia, M. $2012 b$. Antihyperglycemic, antihyperlipidemic and antioxidant activities of traditional aqueous extract of Zygophyllum album in streptozotocin diabetic mice. Pathophysiology, 19: 35-42.

El Ghoul, J., and Ben-Attia, M., 2014. Vasorelaxant effects of aqueous extract of Zygophyllum Album and antihyperglycemic activities in streptozotocin-induced diabetic mice. J. Diabetes Metab. 5: 426.

Ellman, G.L. 1959. Tissue sulfhydryl groups, Arch. Biochem. Biophys. 82: 70 - 77.

Erstfeld, K.M. 1999. Environmental fate of synthetic pyrethroids during spray drift and field runoff treatments in aquatic microcosms. Chemosphere, 39: 1737-1969.

Evans, J.L., Goldfine, I.D., Maddux, B.A., and Grodsky, G.M. 2003. Are oxidative stressactivated signaling pathways mediators of insulin resistance and beta-cell dysfunction. Diabetes, 52: 1-8.

Flohe, L., and Gunzler, W.A. 1984. Assays of glutathione peroxidase. Methods Enzymol. 105: $114-121$.

Gupta, D., Raju, J., Prakash, J.R., and Baquer, N.Z. 1999. Change in the lipid profile, lipogenic and related enzymes in the livers of experimental diabetic rats, effect of insulin and vanadate. Diabetes Res. Clin. Pract. 46: 1-7.

Hammad, I., and Qari, S.H. 2010. Genetic diversity among Zygophyllum (Zygophyllaceae) populations based on RAPD analysis. Genet. Mol. Res. 9: 2412-2420.

Harrower, A.D. 1994. Comparison of efficacy, secondary failure rate, and complications of sulfonylureas. J. Diabetes Complication, 8: 201- 203.

Hussein, S.R., Marzouk, M.M., Ibrahim, L.F., Kawashty, S.A., and Saleh, N.A.M. 2011. Flavonoids of Zygophyllum album L.f. and Zygophyllum simplex L., (Zygophyllaceae). Biochem. Syst. Ecol. 39: 778-780. 
562 Ibiang, Y.B., Ekaluo, U.B., Nta, A.I., Ikpeme, E.V., Ekanem, B.E., et al. 2013. Effect of 563 deltamethrin and ridomil on serum biochemical parameters in the rat :Rattus Norvegius. Eur.

564 J. Toxicol. Sci. 5: 2052-5230.

565

566

567

568

569

570

571

572

573

574

575

576

577

578

579

580

581

582

583

584

585

586

587

588

589

590

591

592

593

594

595

596

597

598

599

600

601

602

603

604

605
Jaouhari, J.T., Lazrek, H.B., and Jana, M. 2000. The hypoglycemic activity of Zygophyllum gaetulum extracts in alloxan induced hyperglycemic rats. J. Ethnopharmacol. 69: 17-20.

John, P.J., and Prakash, A., 2003. Bioaccumulation of pesticides on some organs of fresh water catfish Mystis vitatus. Bull. Environ. Contam. Toxicol. 70: 1013-1016.

Joshi, A.K., and Rajini, P.S. 2009. Reversible hyperglycemia in rats following acute exposure to acephate, an organophosphorus insecticide: role of gluconeogenesis. Toxicology, 257: 40 45 .

Kamath,V., and Rajini P.S. 2007. Altered glucose homeostasis and oxidative impairment in pancreas of rats subjected to dimethoate intoxication. Toxicology, 231: 137-146.

Kamath, V., Joshi A.K.R., and Rajini P.S. 2008. Dimethoate induced biochemical perturbations in rat pancreas and its attenuation by cashew nut skin extract. Pestic. Biochem. Physiol. 90: 58-65.

Kiefer, F., and Wiedmann, K. 2004. Combined therapy: what does acamprosate and naltrexone combination tell us? Alcohol Alcohol, 39: 542-547.

Koeing, R.J., Peterson, C.M., Jone, R.L., Saudek, C., Lehman, M., et al. 1976. Correlation of glucose regulation and haemoglobin A1c in diabetes mellitus. N. Engl. J. Med. 295: 417- 420.

Koida, H., and Oda, T. 1959. Pathological occurrence of glucose-6-phosphatase in liver. diseases. Clin. Chem. Acta, 4: 554-561.

Ksheerasagar, R.L., and Kaliwal, B.B. 2003. Temporal effects of mancozeb on testes, accessory reproductive organs and biochemical constituents in albino mice. Environ. Toxicol. Phar. 15: 9-17.

Ksouri, R., Megdiche, W., Falleh, H., Trabelsi, N., Boulaaba, M., et al. 2008. Influence of biological, environmental and technical factors on phenolic content and antioxidant activities of Tunisian halophytes. C. R. Biologies, 331: 865-873.

Ksouri,W.M., Mdini,F., Mkadmi,K., Legaut, J., and Magné, C. 2013. LC-ESI-TOF-MS identification of bioactive secondary metabolites involved in the antioxidant, antiinflammatory and anticancer activities of the edible halophyte Zygophyllum album Desf. Food Chem. 139: 1073-1080.

Lapeir, T.K., and Rodnick, K.J. 2001. Effects of aerobic exercise on energy metabolism in the hypertensive rat heart. Phys. Ther. 81: 1006-1017.

Lasram, M.M., Annabi, A.B., Rezg, R., Elj, N., Slimen, S., et al. 2009. Metabolic disorders of acute exposure to malathion in adult Wistar rats. J. Hazard. Mater. 163: 1052-1055.

Levine, R.L., Garland, D., Oliver, C.N., Amici, A., Climent, I., et al. 1990. Determination of carbonyl content in oxidatively modified proteins. Methods Enzymol. 186: 464- 478. 
606

607

608

609

610

611

612

613

614

615

616

617

618

619

620

621

622

623

624

625

626

627

628

629

630

631

632

633

634

635

636

637

638

639

640

641

642

643

644

645

646

647

648

649

650

651

652

653

Marklund, S., and Marklund,G. 1974. Involvement of the super-oxide anion radical in the autoxidation of pyrogallol and a convenient assay for superoxide dismutase. Eur. J. Biochem. 47: 469-474.

Mnafgui, K., Hamden, K., Ben Salah, H., Kchaou, M., Nasri, M., et al. 2012. Inhibitory Activities of Zygophyllum album: A Natural Weight-Lowering Plant on Key Enzymes in High-Fat Diet-Fed Rats. Evid. Based Complement. Alternat. Med. 2012: ID 620384, 9 p.

Mnafgui, K., Kchaou, M., Hamden, K., Derbali, F., Slama, S., et al. 2014. Inhibition of carbohydrate and lipid digestive enzymes activities by Zygophyllum album extracts: effect on blood and pancreas inflammatory biomarkers in alloxan-induced diabetic rats. J. Physiol. Biochem. 70: 93-106.

Mnafgui, K., Kchaou, M., Ben Salah, H., Hajji, R., Khabbabi, G., et al. 2015. Essential oil of Zygophyllum album inhibits key-digestive enzymes related to diabetes and hypertension and attenuates symptoms of diarrhea in alloxan-induced diabetic rats. Pharm. Biol. 6: 1-8.

Montgomery, M.P., Kamel, F., Saldana, T.M., Alavanja, M.C., and Sandler, D.P., 2008. Incident diabetes and pesticide exposure among licensed pesticide applicators: Agricultural Health Study, 1993-2003. Am. J. Epidemiol. 167: 1235-1246.

Moustafa, A.M.Y., Khodhair, A.I., Hammouda, F.M., and Husseiny, H.A. 2007. Phytochemical and toxicological studies of Zygophyllum album L.F. J. Pharma. Toxicology, 2: $220-237$.

Murali, R., Srinivasan, S., and Ashokkumar, N. 2013. Antihyperglycemic effect of fraxetin on hepatic key enzymes of carbohydrate metabolism in streptozotocin-induced diabetic rats. Biochimie, 95: 1848-1854.

Nieymer, H., Gonzalez, C., and Rozzi, R. 1961. Influence of diet on liver phosphorylase: effects of fasting and refeeding. J. Biol. Chem. 236:610-613.

Ong, K.C., and Khoo, H.E. 2000. Effects of myricetin on glycemia and glycogen metabolism in diabetic rats. Life Sci. 67: 1695-1705.

Pari, L., and Latha, M. 2005. Antidiabetic effect of Scopariadulcis: effect on lipid peroxidation in streptozotocin diabetes. Gen. Physiol. Biophys. 24: 13-26.

Pari, L., and Srinivasan, S. 2010. Antihyperglycemic effect of diosmin on hepatic key enzymes of carbohydrate metabolism in streptozotocin-nicotinamide-induced diabetic rats. Biomed. Pharmacotherapy, 64: 477-481.

Parker, G., Taylor, R., Jones, D., Mc. and Clain, D. 2004. Hyperglycemia and inhibition of glycogen synthase in streptozotocin-treated mice: role of O-linked $\mathrm{N}$ acetyl gluco-samine. J. Biol. Chem. 279: $20636-20642$.

Pederson, B.A., Schroeder, J.M., Parker, G.E., Smith, M.W., DePaoli-Roach, A.A., et al. 2005. Glucose metabolism in mice lacking muscle glycogen synthase. Diabetes, 54: 34663473. 
654 Pournourmohammadi, S., Farzami, B., Ostad, S.N., Azizi, E., and Abdollahi, M., 2005. 655 Effects of malathionsubchronic exposure on rat skeletal muscle glucose metabolism. 656 Environ. Toxicol. Pharmacol. 19: 169-191.

657 Raafat, N., Abass, M.A., and Salem, H.M. 2012. Malathion exposure and insulin resistance 658 among a group of farmers in Al-Sharkia governorate. Clin. Biochem. 45: 1591-1595.

659 Ranjbar, A., Ghahremani, M.H., Sharifzadeh, M., Golestani, A., Ghazi-Khansari, M., et al. 660 2010. Protection by pentoxifylline of malathion-induced toxic stress and mitochondrial 661 damage in rat brain. Hum. Exp. Toxicol. 29: 851-864.

662 Ruch, R.J., Cheng, S.J., and Klaunji, J.E. 1989. Prevention of cytotoxicity and inhibition of 663 intercellular communication by antioxidant catechins isolated from Chinese green tea. 664 Carcinogenesis, 10: 1003-1008.

665

666

667

668

669

670

671

672

673

674

675

676

677

678

Saldana, T.M., Basso, O., Hoppin, J.A., Baird, D.D., Knott, C., et al. 2007. Pesticide exposure and self-reported gestational diabetes mellitus in the Agricultural Health Study. Diabetes Care, 30: 529-534.

Sivakumar, S., and Subramanian, S.P. 2009. Pancreatic tissue protective nature of D-Pinitol studied in streptozotocin-mediated oxidative stress in experimental diabetic rats. E. J. Pharm. 622: $65-70$.

Slotkin, T.A. 2011. Does early-life exposure to organophosphate insecticides lead to prediabetes and obesity? Reprod. Toxicol. 31: 297-301.

Smirnoff, N., and Cumbes, Q.J. 1989. Hydroxyl radical scavenging activity of compatible Solutes. Phytochemistry, 28: 1057-1060.

679 Soardo, G., Donnini, D., Domenis, L., Catena, C., De Silvestri, D., et al. 2011. Oxidative 680 stress is activated by free fatty acids in cultured human hepatocytes._Metab. Syndr. Relat. 681 Disord. 9: 397-401

682

Sundaram, R., Naresh, R., Shanthi, P., and Sachdanandam, P. 2012. Efficacy of 20-OHecdysone on hepatic key enzymes of carbohydrate metabolism in streptozotocin induced diabetic rats. Phytomedicine, 19: 725-729.

Tarantino, G., Scopacasa, F., Colao, A., Capone, D., Tarantino, M., et al. $2011 a$. Serum Bcl-2 concentrations in overweight-obese subjects with nonalcoholic fatty liver disease. World J. Gastroenterol. 17: 5280-5288.

690 Tarantino,G., Colao,A., Capone,D., Tarantino, M., Conca P., et al. 2011b. Circulating levels

691 of cytochrome $\mathrm{C}$, gamma-glutamyl transferase, triglycerides and unconjugated bilirubin in

692 overweight/obese patients with non-alcoholic fatty liver disease. J. Biol. Regul. Homeost.

693 Agents, 25:47-56.

694

695

696 Tuzmen, N., Candan, N., Kaya, E., and Demiryas N. 2008. Biochemical effects of 697 chlorpyrifos and deltamethrin on altered antioxidant defense mechanisms and lipid 698 peroxidation in rat liver. Cell. Biochem. Funct. 26: 119-124. 
699 Videla, L.A., Rodrigo, R., Orellana, M., Fernandez, V., Tappia, G., et al. 2004. Oxidative 700 stress-related parameters in the liver of non-alcoholic fatty liver disease patients. Clinical 701 Science Mar. 106: 261-268

702

703 Wolansky, M.J., and Harrill, J.A. 2008. Neurobehavioral toxicology of pyrethroid insecticides 704

705

706

707

708

709 in adult animals: a critical review. Neurotoxicol. Teratol. 30: 55- 78.

Yolanda, B.L, and Adriana, G.C. 2006. Effects of dietary polyunsaturated n-3 fatty acids on dyslipidemia and insulin resistance in rodents and humans. J. Nutr. Biochem. 17: 1-13.

Yousef, M.I., El-Demerdash, F.M., Kamel, K.I., and Al-Salhen, K.S. 2003. Changes in some hematological and biochemical indices of rabbits induced by isoflavones and cypermethrin.

711 Toxicology, 189: 223-234. 


\section{Table 1}

Effect of methanolic extract of zygophyllum album leaves (MEZAL) on changes in blood glucose level, plasma insulin level, total hemoglobin $(\mathrm{Hb})$ and glycosylated hemoglobin $(\mathrm{HbA} 1 \mathrm{c})$ in control and experimental rats.

\begin{tabular}{lllll}
\hline Parameters and Treatments & Control & MEZAL & DLM & DLM + MEZAL \\
\hline Glucose $(\mathrm{mg} / \mathrm{dl})$ & $122.3 \pm 1.65$ & $123.3 \pm 2.42$ & $131.7 \pm 1.81^{* * *}$ & $124.4 \pm 3.03^{* * *}$ \\
Insulin $(\mu \mathrm{U} / \mathrm{ml})$ & $17.03 \pm 1.55$ & $15.63 \pm 0.49$ & $9.2 \pm 0.55^{* * *}$ & $13.13 \pm 0.73^{* *}$ \\
Total hemoglobin $(\mathrm{Hb})(\mathrm{g} / \mathrm{dl})$ & $16.49 \pm 0.94$ & $15.99 \pm 0.89$ & $12.17 \pm 1.31^{* * *}$ & $14.19 \pm 1.08^{*}$ \\
$\begin{array}{l}\text { Glycated hemoglobin }(\mathrm{HbA} 1 \mathrm{c}) \\
(\mathrm{mg} / \mathrm{g} \mathrm{Hb})\end{array}$ & $0.36 \pm 0.03$ & $0.36 \pm 0.07$ & $1.01 \pm 0.07^{* * *}$ & $0.52 \pm 0.04^{* ¥ *}$ \\
\hline
\end{tabular}

Values are presented as a mean $\pm \mathrm{SD}(\mathrm{n}=6) .{ }^{*} \mathrm{p}<0.05, * * \mathrm{p}<0.01, * * * \mathrm{P}<0.001$ vs control; and ${ }^{¥} \mathrm{P}<0.05,{ }^{¥ ¥} \mathrm{P}<0.01,{ }^{¥ ¥ ¥} \mathrm{P}<0.001$ vs DLM 


\section{Table 2}

Effect of methanolic extract of zygophyllum album leaves (MEZAL) treatment on glycogen content and hepatic activities of Hexokinase, Glucose-6-phosphatase and Glycogen phosphorylase in control and experimental rats.

\begin{tabular}{|c|c|c|c|c|}
\hline Parameters and Treatments & Control & MEZAL & DLM & DLM + MEZAL \\
\hline $\begin{array}{l}\text { Hexokinase }(\mu \mathrm{mol} \text { glucose } \\
\text { phosphorylated } / \mathrm{min} / \mathrm{mg} \text { of protein) }\end{array}$ & $21.72 \pm 1.23$ & $20.43 \pm 1.42$ & $10.37 \pm 0.6^{* * *}$ & $15.47 \pm 0.68^{¥ ¥}$ \\
\hline $\begin{array}{l}\text { Glucose-6-phosphatase ( } \mu \mathrm{mol} \text { of } \mathrm{Pi} \\
\text { liberated } / \mathrm{min} / \mathrm{mg} \text { protein) }\end{array}$ & $20.57 \pm 1.24$ & $18.82 \pm 1.6$ & $23.83 \pm 2.55^{*}$ & $19.97 \pm 1.81$ \\
\hline $\begin{array}{l}\text { Glycogen phosphorylase ( } \mu \mathrm{mol} \text { of } \\
\mathrm{Pi} \text { liberated } / \mathrm{min} / \mathrm{mg} \text { protein) }\end{array}$ & $10.92 \pm 1.07$ & $11.30 \pm 1.13$ & $12.78 \pm 0.84 *$ & $12.99 \pm 1.18^{¥}$ \\
\hline Glycogen (mg /g of liver) & $11.47 \pm 1.21$ & $11.04 \pm 1.05$ & $7.18 \pm 1.08 * * *$ & $9.28 \pm 1.14^{¥}$ \\
\hline
\end{tabular}

Values are presented as a mean $\pm \mathrm{SD}(\mathrm{n}=6) .{ }^{*} \mathrm{p}<0.05, * * \mathrm{p}<0.01, * * * \mathrm{P}<0.001$ vs control; and ${ }^{¥} \mathrm{P}<0.05,{ }^{¥ ¥} \mathrm{P}<0.01,{ }^{¥ ¥ ¥} \mathrm{P}<0.001$ vs DLM 


\section{Table 3}

Effects of methanolic extract of zygophyllum album leaves (MEZAL) on lipid peroxidation (TBARS) and protein carbonyls (PC) contents in the pancreatic tissue of control (C) and experimental rats.

\begin{tabular}{|c|c|c|c|c|}
\hline Parameters and treatments & $\mathbf{C}$ & MEZA & DLM & DLM + MEZA \\
\hline $\begin{array}{l}\text { TBARS (nmoles MDA/ mg } \\
\text { protein) }\end{array}$ & $9.48 \pm 0.51$ & $9.1 \pm 0.48$ & $15.05 \pm 1.03^{* * *}$ & $12.9 \pm 1.05^{\mathrm{q \Psi}}$ \\
\hline PC (nmoles/mg protein) & $4.27 \pm 0.17$ & $4.1 \pm 0.59$ & $6.73 \pm 0.44^{* * *}$ & $5.72 \pm 0.59^{¥ ¥}$ \\
\hline
\end{tabular}

Values are presented as a mean $\pm \mathrm{SD}(\mathrm{n}=6){ }^{*} \mathrm{p}<0.05, * * \mathrm{p}<0.01, * * * \mathrm{P}<0.001$ vs control; and ${ }^{¥} \mathrm{P}<0.05,{ }^{¥ ¥} \mathrm{P}<0.01,{ }^{¥ ¥ ¥} \mathrm{P}<0.001$ vs DLM 


\section{Table 4}

Effects of methanolic extract of zygophyllum album leaves (MEZAL) extract on enzymatic and non-enzymatic antioxidants changes in the pancreatic tissue of control (C) and experimental rats.

\begin{tabular}{lcccc}
\hline Parameters and treatments & C & MEZA & DLM & DLM + MEZA \\
\hline GSH $(\mu$ mole $/$ g tissue) & $207.9 \pm 3.05$ & $203.9 \pm 2.74$ & $192.4 \pm 1.98^{* * *}$ & $196.6 \pm 1.39^{¥}$ \\
SOD $(\mathrm{U} / \mathrm{mg}$ protein) & $15.05 \pm 0.59$ & $15.47 \pm 0.78$ & $13.87 \pm 0.79^{*}$ & $15.11 \pm 0.65^{\ddagger}$ \\
CAT $(\mu \mathrm{mol}$ of H2O2 & $14.23 \pm 0.75$ & $14.97 \pm 0.71$ & $11.95 \pm 1.03^{* * *}$ & $13.63 \pm 0.37^{¥ ¥}$ \\
destroyed/min/mg protein) & & & \\
GPx(nmol of NADPH & $8.97 \pm 0.52$ & $9.68 \pm 0.95$ & $7.22 \pm 0.58^{* *}$ & $8.56 \pm 0.75^{¥}$ \\
oxidized/min/mg protein) & & & & \\
\hline
\end{tabular}

Values are presented as a mean $\pm \mathrm{SD}(\mathrm{n}=6) .{ }^{*} \mathrm{p}<0.05,{ }^{* *} \mathrm{p}<0.01, * * * \mathrm{P}<0.001$ vs control; and ${ }^{¥} \mathrm{P}<0.05,{ }^{¥ ¥} \mathrm{P}<0.01,{ }^{q y \Psi} \mathrm{P}<0.001$ vs DLM 


\section{Figure captions}

Figure 1. Free radical scavenging activities of methanol extract of Z.album leaves. (A) hydroxyl radical scavenging activities of various concentrations of MEZAL (100-600 $\mu \mathrm{g} / \mathrm{ml})$ and BHT. (B) hydrogen peroxide scavenging activities of MEZAL $(100-600 \mu \mathrm{g} / \mathrm{ml})$ and BHT.

Figure2. Photomicrographs of pancreatic tissues in control and experimental treated rats. Pancreatic tissue sections stained with hematoxylin-eosin ( $\mathrm{G} \times$ 400). (A) in control rats, representative micrograph shows a normal pancreatic islet $(\rightarrow)$, (B) treated with MEZAL $(400 \mathrm{mg} / \mathrm{kg})$ alone showing normal cluster islet cells $\leftrightarrow$ ); (C) in deltamethrin treated rats: showing a significant reduction in the size of islets, damaged $\beta$-cell population and extensive necrotic changes also (\&), (D) co-treated with deltamethrin and MEZAL, representative micrograph show the increase of islets size and the disappearance of necrotic changes, showing apparently normal architecture $(\rightarrow)$

Figure 3. Photomicrograph of the liver tissues in control and experimental treated rats (sections stained with Periodic acid-Schiff (PAS) for detection of glycogen deposition). (A) in control rats and (B) in MEZAL treated groups, representative micrographs showing a positive PAS- reaction, with magenta color staining and a homogenously glycogen distribution in the hepatocytes $(\rightarrow),(\mathrm{C})$ in deltamethrin treated rat showing a significant apparent decrease of glycogen deposition in the hepatocytes ( \&). (D) co-treated with deltamethrin and MEZAL, representative micrographs shown a remarkable increase in glycogen deposition in hepatocytes close to that of control rats ( $\bigcirc$ ). Original magnification $(\mathrm{G} x \mathrm{400})$. 

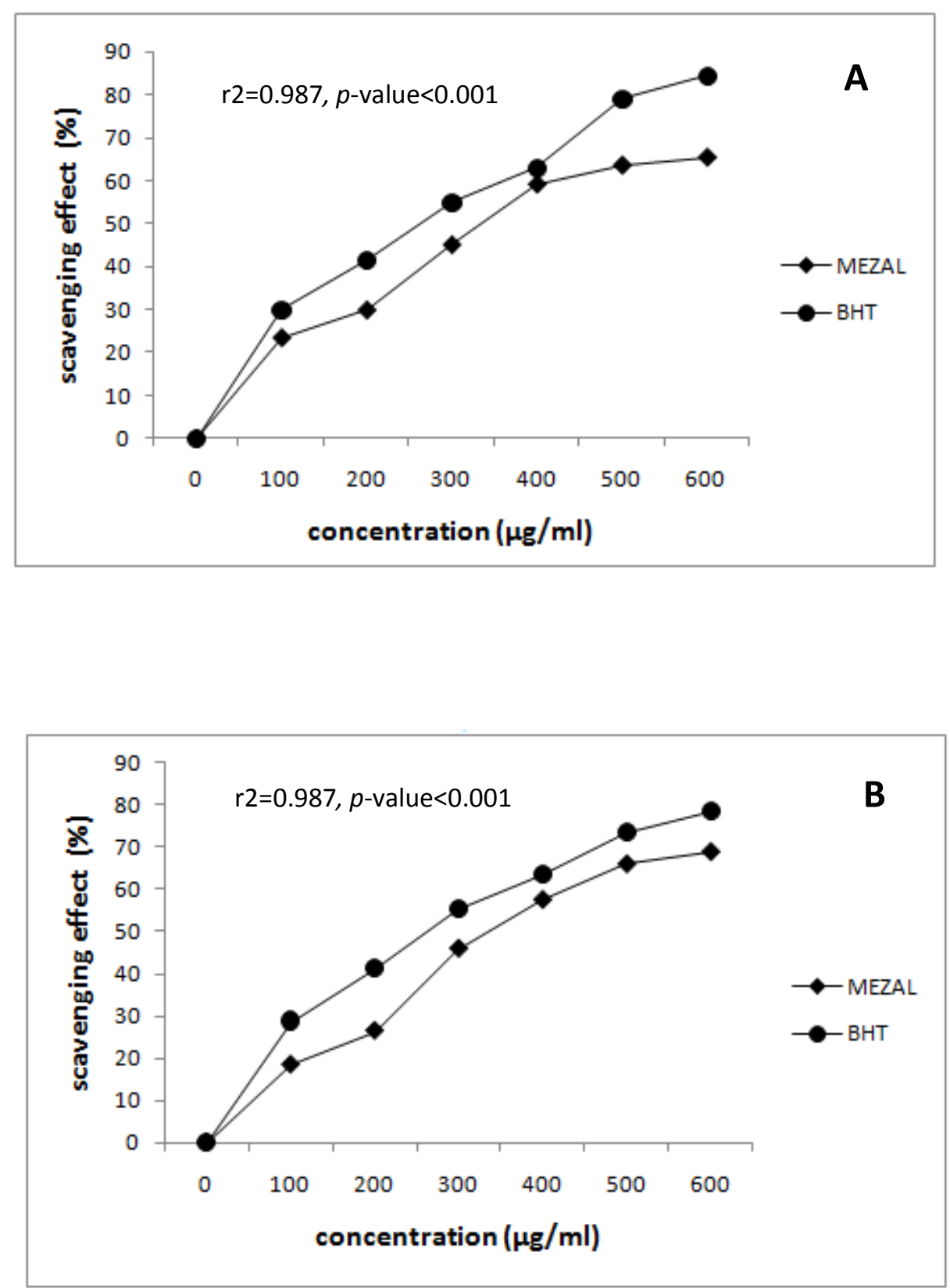

Figure 1 

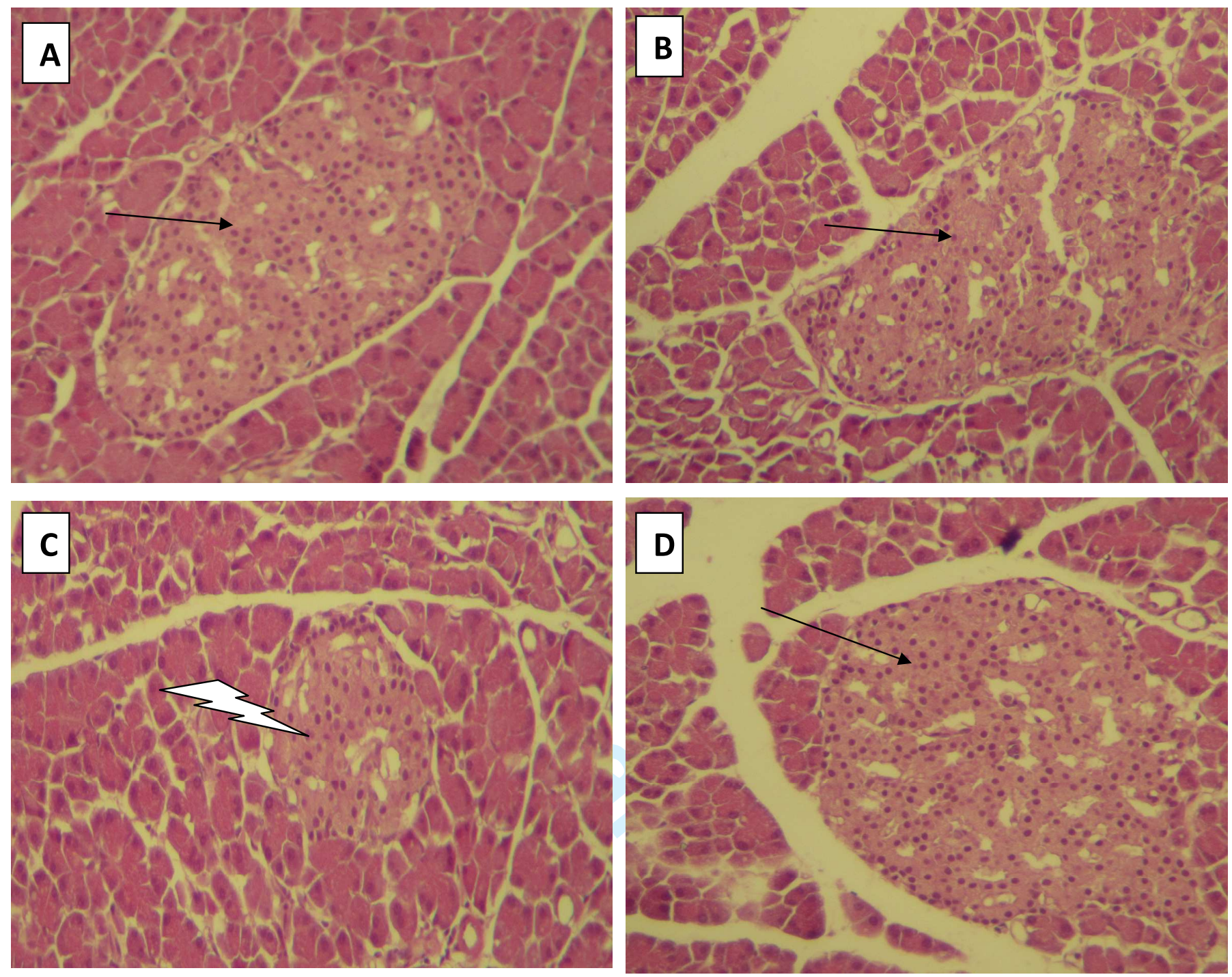

Figure 2 

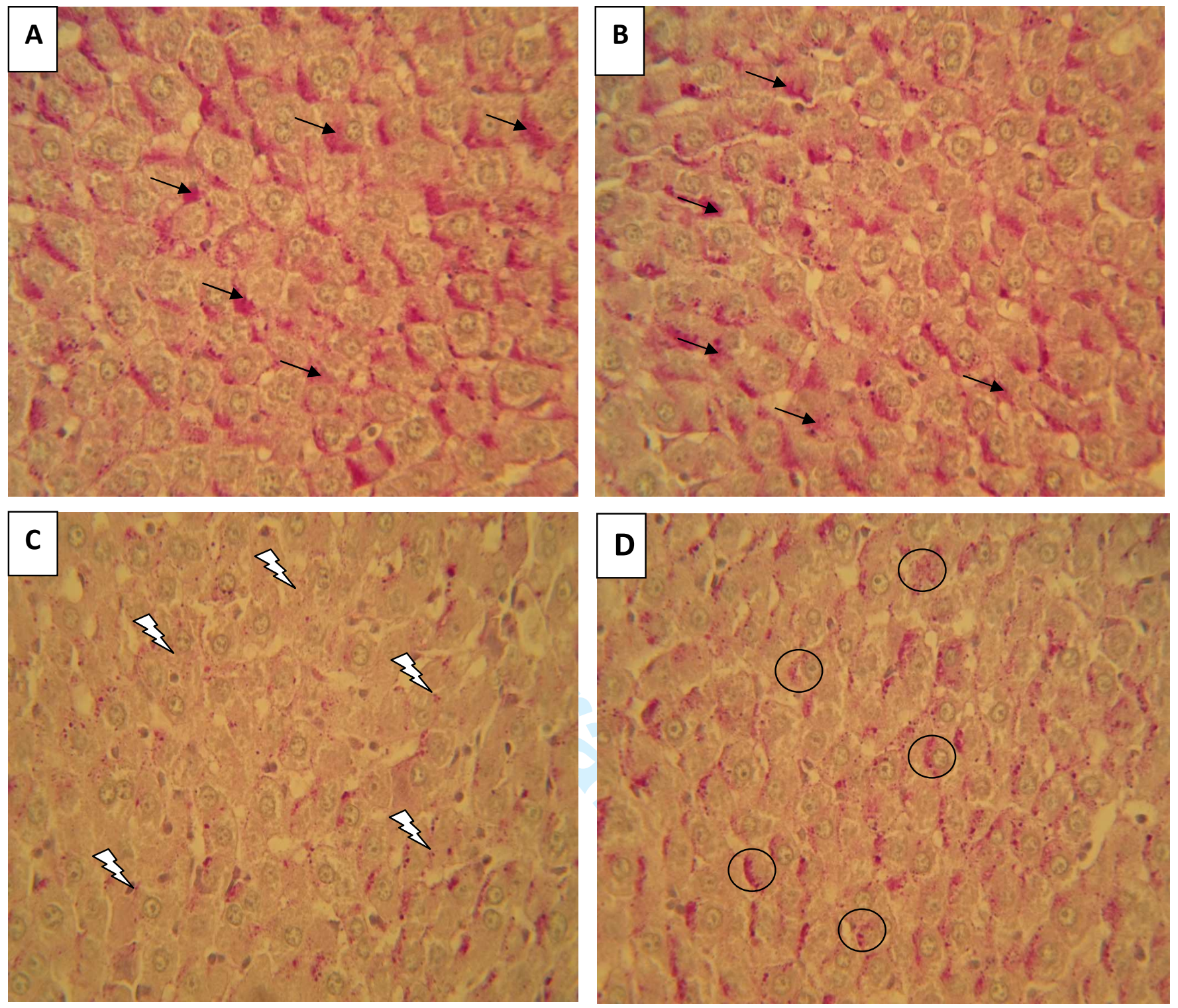

Figure 3 